\title{
O Coringa: a representação imagética da loucura
}

\section{The Joker: the image representation of madness}

\author{
Levy Henrique Bittencourt Neto ${ }^{1}$
}

\section{Resumo}

$\mathrm{O}$ artigo tem como objeto de estudo imagens retiradas da história em quadrinhos Coringa, lançada no ano de 2009 no Brasil pela editora Panini Comics. Como o próprio nome sugere, essa HQ é focada no vilão, na sua tentativa de restabelecer seu antigo poder na cidade de Gotham, após anos de confinamento no Asilo Arkham. De alguma forma, ele consegue convencer seus médicos de que está são. Não será analisada a história em quadrinhos como um todo, mas sim recortes imagéticos e algumas linhas de diálogo que dão conta de exemplificar a insanidade crônica do protagonista. Para tanto, utilizaram-sese como método analítico as categorias fenomenológicas de Charles Sanders Peirce, e a tricotomia do signo em relação ao objeto dinâmico - ícone, índice e símbolo.

Palavras-chave: Semiótica peirceana. Fenomenologia. História em quadrinhos. Coringa.

\begin{abstract}
The object of study in this article is images taken from 'Joker' comic strips, published in Brazil in 2009 by Panini Comics. As the name suggests, these comics focus on the villain, on his attempt to restore his power in Gotham City, after years of confinement in Arkham Asylum. Somehow he can convince his doctors that he is sane. The analysis does not consider each story as a whole, but only isolated image clippings and a few dialogue lines which illustrate the chronic insanity of the protagonist. For that matter, the analytical methods utilized were the phenomenological categories of Charles Sanders Peirce and the trichotomy of sign in relation to the dynamic object - icon, index and symbol.
\end{abstract}

Keywords: Peircean semiotics. Phenomenology. Comic strips. The Joker.

\section{Introdução}

Dentre todos os incontáveis vilões das histórias em quadrinhos, o Coringa é um personagem de relevo. O palhaço do crime já teve várias versões em muitas mídias diferentes, desde o bobo e cômico da série de TV dos anos 60 até o psicopata niilista do filme O Cavaleiro das Trevas, encarnado, de maneira brilhante e assustadora, por Heath Leadger. Foi essa última corporificação que, provavelmente, serviu de base para a história em quadrinhos Coringa, roteirizada por Brian Azarello e ilustrada por Lee Bermejo.

Aproveitando os conceitos retirados do filme $\mathrm{O}$ Cavaleiro das Trevas, Azarello e Bermejo (2009) apresentam o vilão com uma cicatriz terrível no rosto, que o deixa sempre com um sorriso demente e cruel. Sem piadas nem brincadeiras, o Coringa nessa história em quadrinhos é o retrato da loucura; o psicopata que assusta até outros vilões do universo do Batman, como o Pingüim e o Duas-Caras.

Com o objetivo de traçar a representação da loucura através das imagens, foram escolhidas quatro páginas da graphic novel, e a cada uma delas ${ }^{2}$ foi atribuída uma categoria fenomenológica de C.S. Peirce. Para auxiliar a análise dessas páginas, optouse pela tricotomia do signo em relação ao objeto dinâmico - ícone, índice e símbolo.

\footnotetext{
1 Graduado no ano de 2008 em Comunicação Social: Jornalismo pela Universidade Estadual de Londrina. Especialista em fotografia pela mesma universidade. Mestrando em Tecnologias da Inteligência e Design Digital na PUC - SP.

2 Com exceção da secundidade, que ficou com duas páginas.
} 


\section{A Arte Seqüencial}

As histórias em quadrinhos, assim como o cinema e a animação, são consideradas artes visuais seqüenciais, isto é, uma seqüência de quadros que narram uma história (EISNER, 1989; MCCLOUD, 1995). A característica que difere as HQs de seus pares isolados - ilustração e texto - é justamente a amalgama desses dois signos visuais para a criação narrativa. "A configuração geral da revista de quadrinhos apresenta uma sobreposição de palavras e imagens [...]. A leitura da revista de quadrinhos é um ato de percepção estética e de esforço intelectual." (EISNER, 1989, p. 8).

Pode-se pensar que as animações também são artes visuais seqüenciais - mesmo o cinema é formado por uma série de quadros estáticos. Então, como diferenciar essas três artes? Scott McCloud (1995, p. 9) afirma que histórias em quadrinhos são "imagens pictóricas e outras justapostas em seqüência deliberada destinadas a transmitir informações e/ou a produzir uma resposta no espectador". Em outras palavras, enquanto a projeção cinematográfica se desdobra num mesmo espaço - a tela -, as histórias em quadrinhos são ordenadas em várias telas em seqüência.

As primeiras histórias em quadrinhos, conforme se conhece hoje, surgiram na década de 30 do século XX, como uma coleção de obras curtas e aleatórias (EISNER, 1989). Entre 1940 e o início de 1960, essa forma de arte gráfica não era voltada para o público adulto. Nesse período "a indústria aceitava, comumente, o perfil do leitor de quadrinhos como o de uma 'criança de 10 anos, do interior'. Um adulto ler histórias em quadrinhos era considerado sinal de pouca inteligência" (EISNER, 1989, p. 138). Apesar desse estigma, a arte seqüencial não é nenhuma novidade para a Humanidade. Esse tipo de arte é encontrado nas tumbas dos antigos egípcios, em tapeçarias medievais e nas civilizações précolombianas mexicanas, além de muitos outros exemplos históricos (MCCLOUD, 1995, p. 1021).

Apenas no final dos anos 70 do século passado é que foram criadas as chamadas graphic novels (EISNER, 1989). Esse tipo de narrativa é uma história fechada em uma, ou várias edições, com começo, meio e fim - como um romance, ou um filme. A revista Coringa, o objeto de estudo, se enquadra nessa categoria de histórias em quadrinhos.

\section{O Fenômeno e o Signo}

O filósofo estadunidense Charles Sanders Peirce formulou que o fenômeno - ou phaneron - é "o total coletivo de tudo aquilo que está de alguma forma ou sentido apresentando-se a mente, a propósito daquilo ser correspondente a algo real ou não". (CP 1.284) ${ }^{3}$. A fenomenologia é a disciplina mais elementar entre as ciências filosóficas, pois é aquela que "se identifica com a experiência comum, estudando, esvaziadas ao máximo de qualquer preconceito, as características dos fenômenos." (PEIRCE apud PIRES, 2008, p. 154).

Em um dos primeiros ensaios de Peirce, publicado em 1868, chamado "sobre uma nova lista de categorias", foi postulada ${ }^{4}$ a existência de apenas três elementos fundamentais que viriam a ser, no futuro, a primeiridade, a secundidade e a terceiridade. Por dezoito anos, essa descoberta fora posta de lado, mas "as pesquisas indutivas, que Peirce realizou nas várias áreas das ciências, foram lhe trazendo,

3 Será usada a referência usual a esta obra: de CP de Charles Sanders Peirce que indica Collected Papers; o primeiro número corresponde ao volume e o segundo, ao parágrafo.

4 Ver o ensaio original em: < http://www.peirce.org/writings/p32.html > ou em CP $1.545-559$. 
ao longo dos anos, confirmações empíricas para as categorias" (SANTAELLA, 1994, p. 115). As categorias fenomenológicas formam a base de todo o pensamento peirceano. É por meio delas que a monumental arquitetura concebida pelo filósofo ganha uniformidade. Em uma carta de 1904, décadas após seu ensaio, Charles Peirce, ainda que um pouco contrariado, já aceitava a lógica ternária como ponto fundamental de toda a sua teoria.

Esse tipo de noção me é tão pouco agradável como para qualquer outra pessoa e, durante muitos anos, tentei reduzir-lhe a importância e afastar-me dele. Contudo, de há muito, ele me conquistou por completo. Por desagradável que seja atribuir significação tal a números e, acima de tudo, a uma tríade, é tão desagradável quanto verdadeiro (PEIRCE, 1975, p. 136).

Peirce considera que existem três categoriais formais e universais em qualquer fenômeno: primeiridade, secundidade, terceiridade. "As idéias típicas de primeiridade são as qualidades de sentimento, ou meras aparições, [...] independentemente da forma como elas são percebidas ou lembradas" (CP 8.329). A primeiridade envolve sentimento, qualidade, acaso, espontaneidade, originalidade - um instante decisivo, único, sem conexão com o passado ou futuro, ou com qualquer outra coisa além de si mesmo. Pode-se dizer que a primeiridade é o fugidio presente. "Nas palavras de Peirce, "vá sob o azul do firmamento e olhe o que está presente tal como surge aos olhos do artista' (CP 5.44). O que se verá é a liberdade brotando, uma consciência imediata, espontânea e de caráter incondicional" (PIRES, 2008, p. 154).

A secundidade é a categoria fenomenológica do embate, dualidade, ação-reação, matéria, determinação. Ela "está vinculada às relações que mantém dentro do universo da experiência, sendo estas relações puro fato bruto. Uma experiência privada de objetivo é ação e reação, esforço e resistência" (PEIRCE apud PIRES, 2008, p. 156). Charles Peirce usa como exemplo claro de secundidade o passado, pois:

[...] o passado compele o presente, pelo menos de alguma forma. Se você reclamar ao passado que ele está errado e não é razoável, ele rirá. [...] Sua força é força bruta. Então, você é compelido, brutalmente compelido, a admitir que exista tal elemento no mundo da experiência como a força bruta (CP 2.84).

A terceiridade é a categoria da mediação entre o primeiro e o segundo (palavras relativas às outras categorias), tempo, conceitos, generalizações e pensamentos. Ela não é um instante decisivo no tempo, tampouco uma força bruta, mas sim uma cognição que se vincula ao futuro. "Através da generalização do fato bruto, ela proporciona a representação das circunstâncias em que poderão vir a ser. Irá procurar estabelecer as leis gerais que determinarão a conduta auto-controlada para sua efetivação" (PIRES, 2008, p. 157). Qualquer conceito, cognição, lei ou hábito é um terceiro. Esse texto, as regras gramaticais e o alfabeto são alguns exemplos da terceiridade em funcionamento.

As categorias acima são encontradas em todos os fenômenos; são onipresentes e irredutíveis. "Não apenas a terceiridade supõe e envolve as idéias de secundidade e primeiridade, mas nunca seria possível achar no fenômeno qualquer secundidade ou primeiridade que não fosse acompanhada pela terceiridade" (CP 5.90). Algumas vezes, uma categoria se realça mais do que as outras, mas isso não quer dizer que ela seja a única presente no fenômeno, ou a mais importante. As três categorias fenomenológicas necessariamente são interdependentes (CP 5.91).

Aobra de Charles Peirceévasta(SANTAELLA, 1994, p. 107), mas uma disciplina se sobressai a todas outras: a Lógica - ou Semiótica - disciplina 
que se propõe a estudar os signos. O signo pode ser descrito como algo de qualquer espécie - um livro, uma palavra, uma pintura, um grito, um pensamento - determinado por algo diverso de si mesmo, chamado de objeto do signo, e que produz um efeito em alguma mente real ou potencial. O efeito é chamado de interpretante do signo (CP 8.343).

Um signo, ou representamen, é um primeiro que se coloca numa relação triádica genuína tal com um segundo, denominado seu objeto, que é capaz de determinar um terceiro, denominado seu interpretante, que assuma a mesma relação triádica com seu objeto na qual ele próprio está em relação com o mesmo objeto. A relação triádica é genuína (PEIRCE, 2003, p. 48).

Peirce explica que "os princípios e analogias da fenomenologia habilitam-nos a descrever, de um modo vago, quais devem ser as divisões das relações triádicas" (PEIRCE, 2003,p.48). Pode-se dizer "de um modo vago" que a tricotomia signoobjeto-interpretante assume, respectivamente, as categorias fenomenológicas da primeiridadesecundidade-terceiridade. Portanto, existe uma tríade dentro do signo em relação a ele mesmo, duas tríades para os objetos - imediato e dinâmico - e três tríades para os interpretantes - imediato, dinâmico e final. Essa capilaridade dos signos é desnecessária no presente artigo; trabalhar-se-á apenas com a tríade do signo em relação ao seu objeto dinâmico - ícone, índice e símbolo. Não por acaso, é a tríade mais conhecida da semiótica peirceana.
De acordo com Peirce (1975, 2003), um ícone se refere ao objeto por força de caracteres semelhantes, internos a si mesmos, qualidades que ele possuiria existindo ou não objeto para corporificá-lo. Tome-se uma imagem qualquer como exemplo. Ela é um ícone daquilo que representa - mesmo uma fotografia é um signo icônico que se assemelha aos sujeitos fotografados. A imagem fotográfica, assim como qualquer representação imagética, não é o objeto que ela representa.

O índice está conectado existencialmente àquilo que se refere. Uma fotografia do Cristo Redentor é um índice do Rio de Janeiro, sua existência remete necessariamente àquela cidade. Qualquer fotografia, além de ser um ícone, é um índice, pois existe uma ligação luminosa entre o objeto fotografado e a mídia que o representa. "Um índice é um signo que se refere ao objeto que denota em razão de ver-se realmente afetado por aquele objeto" (PEIRCE, 1975, p. 101).

Um símbolo é um signo amparado por um conjunto de leis, entendido como tal por meio de convenções pré-estabelecidas das quais ele é portador. Um crucifixo simboliza o Cristianismo, assim como todas as palavras em qualquer língua formam um conjunto pré-estabelecido de normas. "Um símbolo é um signo que se refere ao objeto que denota por força de uma lei, geralmente uma associação de idéias gerais que opera no sentido de levar o símbolo a ser interpretado como se referindo àquele objeto" (PEIRCE, 1975, p. 102). 


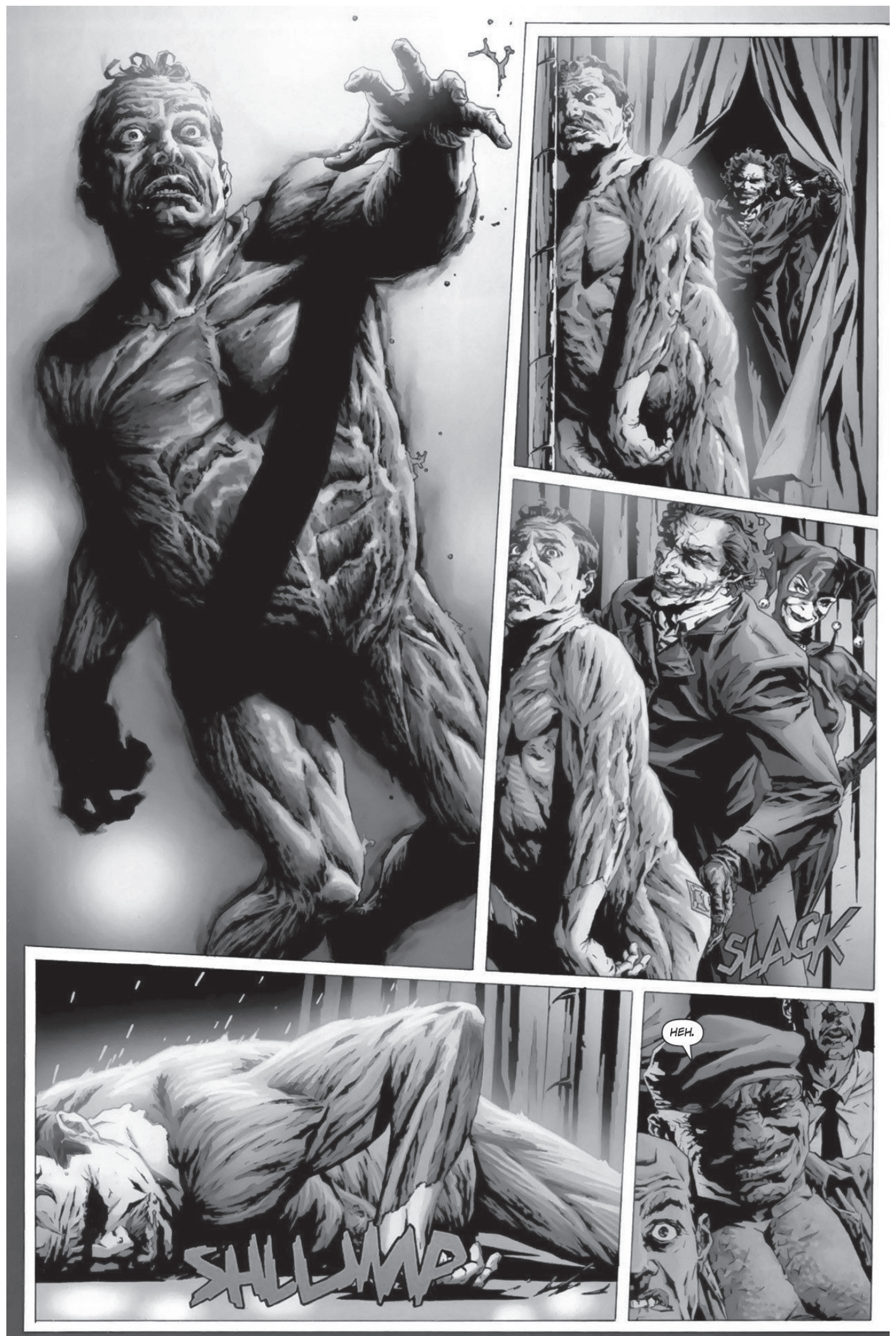

Figura 1. Primeiridade

Fonte: Azarello e Bermejo (2009, p. 26). 
Após ser liberado do Asilo Arkham, Coringa volta ao seu antigo reduto, uma boate que lhe servia de base operacional. Um homem chamado Monty havia ficado responsável pelo andamento dos "negócios", isto é, da manutenção do dinheiro e da influência do palhaço do crime na cidade de Gotham. Monty não realizara a tarefa a contento, e nesse ponto da graphic novel é que o Coringa começa a agir. A página é composta de tons avermelhados, cortinas e luzes magenta, o uniforme da Arlequina (aquela mulher atrás do Coringa) e é claro, a tétrica cena de Monty sem a pele. Essa página inicia as ações do temido vilão na cidade, e mostra de que modo ele irá proceder de agora em diante.

Essa página é o instante decisivo das ações do Coringa. O momento presente em que a máquina da loucura começa a funcionar e a girar descontrolada. De forma geral, a categoria fenomenológica da primeiridade está intimamente presente na composição do caráter do personagem: ele é uma mônada caótica, imprevisível e inconstante. É difícil prever qual será sua próxima ação, e mesmo saber o significado de determinadas ações suas no decorrer do quadrinho. Se a primeiridade é a categoria da indefinição, ela sem dúvida é a categoria mais fundamental do personagem Coringa.

Monty foi exemplarmente punido pela sua falha. É um ícone para que todas as outras pessoas que roubaram, ou devam algo para o Coringa, reflitam acerca disso, pois essas pessoas terão julgamentos semelhantes. O signo icônico é facilmente visualizado nessa página, na sobreposição de tons e formas - as formas e cores da cortina lembram vagamente a dos músculos.

A morte de Monty é um índice de que o psicopata mais temido de Gotham está de volta e ativo. Qual outro vilão de Gotham seria capaz de tamanha brutalidade? Nota-se que a platéia ficou chocada com a terrível cena, exceto o comparsa do Coringa, no último quadro a direita. Seu nome é Crocodilo, e sua expressão é sádica assim como a do próprio Coringa e da Arlequina. Isso é um indicio de que esses três personagens são perturbados - eles permanecem sorridentes visualizando a agonia do ex-gerente.

$\mathrm{O}$ ato de o Coringa colocar uma nota de dinheiro na nádega de Monty é semelhante à atitude que as pessoas geralmente fazem nesse tipo de lugar: coloca-se uma nota na calcinha de uma dançarina, ou prostituta. Isso é um símbolo pré-estabelecido de conduta numa zona de meretrício - paga-se para ver a dança, e, se a dança estiver agradando, paga-se ainda mais. A própria aparência do Coringa é um símbolo. Não é qualquer palhaço e não é qualquer pintura - o rosto branco, olhos com sombras, batom vermelho mal colocado, cabelo verde, terno roxo e a cicatriz em forma de sorriso. Não, não é qualquer palhaço, é o Coringa. 


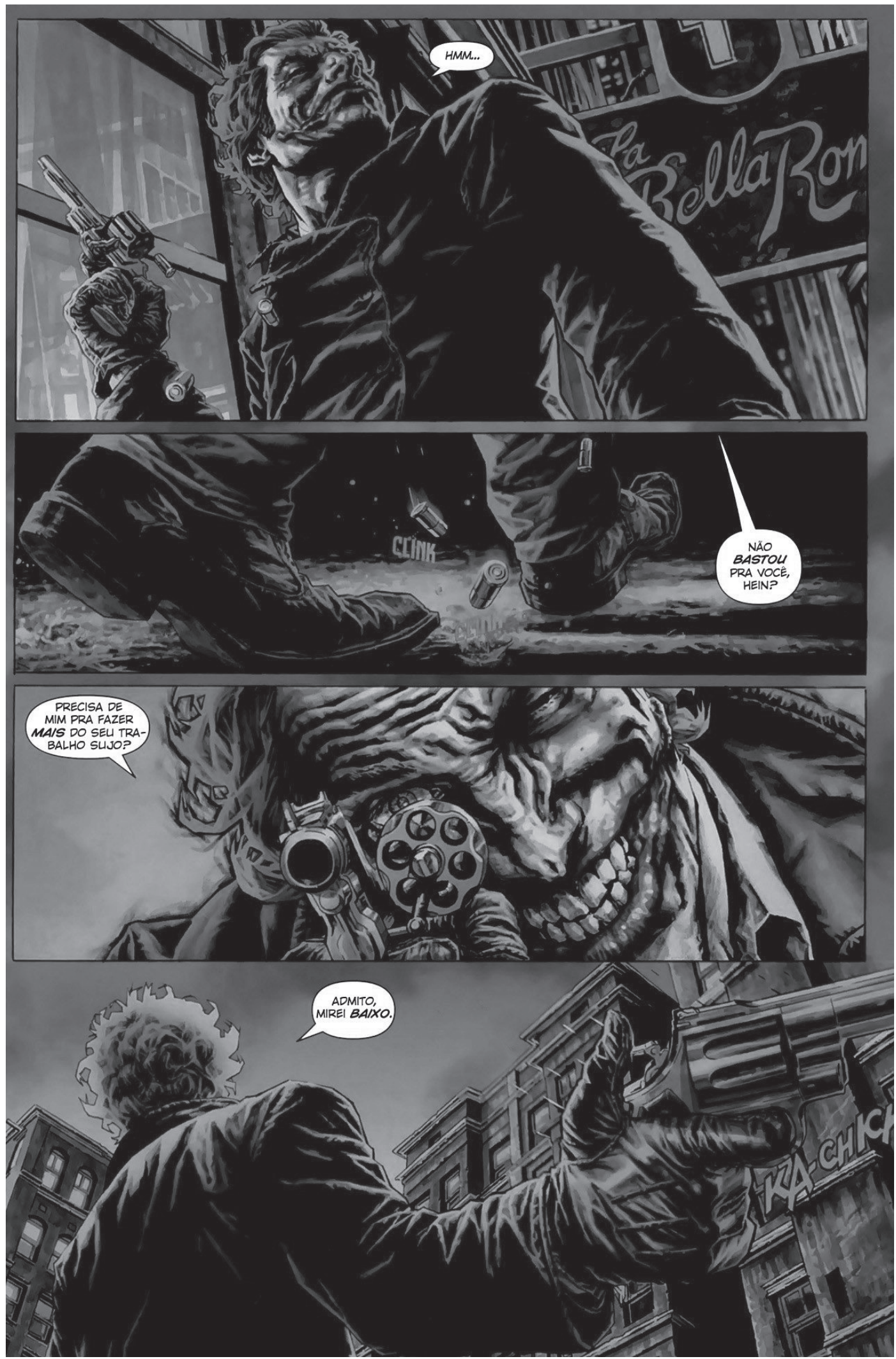

Figura 2. Secundidade

Fonte: Azarello e Bermejo (2009, p. 53-54) 


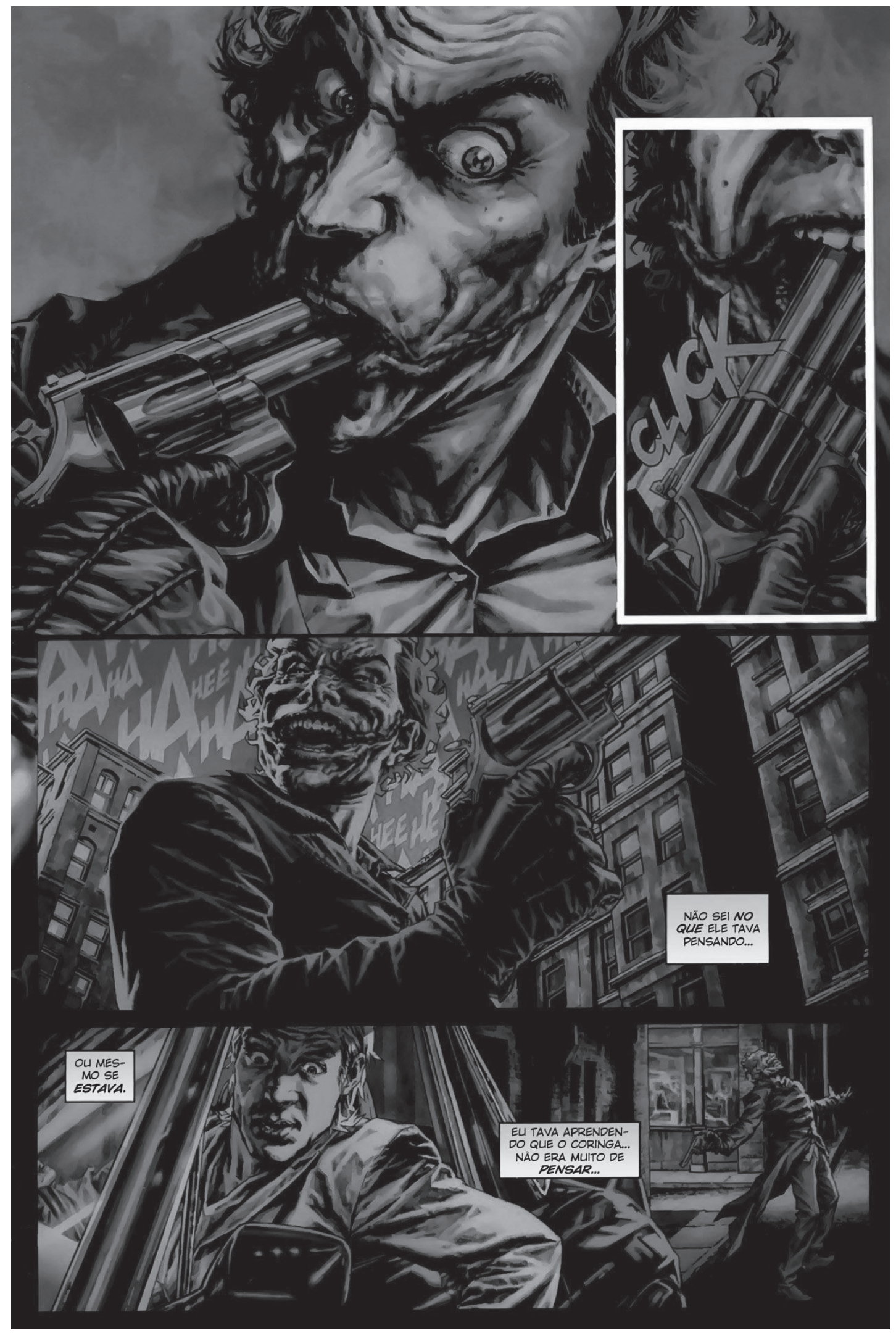

Figura 3. Secundidade

Fonte: Azarello e Bermejo (2009, p. 53-54) 
Como ficou claro na cena da boate, o Coringa não está feliz com a perda de poder e influência na cidade. Ele vai atrás de todos que usurparam algo de seu império do crime. Um a um, os criminosos de Gotham que ousaram se debruçar sobre os espólios abandonados do palhaço insano são mortos. E aos poucos ele vai adquirindo o velho respeito de outrora. Mas o Coringa sabe que está sendo observado, do alto dos edifícios góticos e tenebrosos. O criminoso sabe - ao menos ele acha que sabe - que o seu maior antagonista está por perto, e de alguma forma, por alguma razão, está deixando o psicopata agir.

Não fica claro na graphic novel se o Batman está realmente a observar o Coringa e deixa-o livre. Não combina com o que se sabe do herói vestido de morcego - para ele, toda a vida tem seu valor, mesmo a de um criminoso. Ainda assim, nessas duas páginas, o palhaço age como se o Batman estivesse a poucos metros, atento ao desenrolar das ações. Nessas páginas, há fortes elementos de secundidade: o dualismo Coringa Batman, além do fato do psicopata se comportar como uma força bruta, que cai sobre a cidade de Gotham e força suas ações contra tudo e todos. A categoria da secundidade também é muito marcante na composição do personagem e nas suas ações.

No terceiro quadro da primeira página, vêse que o olho do Coringa se assemelha a uma bala de revolver. Mesmo no primeiro quadro da segunda página, ainda se nota essa semelhança icônica entre a munição e os olhos do vilão. Essa iconicidade do olhar transmite a loucura e poder do personagem para o leitor da HQ. As risadas, no segundo quadro da segunda página, parecem que ecoam por toda a Gotham. É como se essas risadas fossem o ícone de sua loucura que se espalham ao seu redor.

Pode-se dizer que o Coringa de fato acha que o Batman o está observando. Há um indicio dessa pressuposição nas linhas de diálogo e na direção de seu olhar. Em toda a primeira página, ele olha para cima, e supostamente fala com o homemmorcego. O palhaço não está falando com Johnny Frost - o homem do carro - que também é o narrador da história. Nessas duas páginas, o insano protagonista age como se apenas ele e o Batman estivessem ali; a presença de Frost é completamente ignorada.

Brincar de roleta russa é uma ação absurda. Mas nada é absurdo para o Coringa, nem mesmo a possibilidade de estourar a própria cabeça. Peirce (2003, p. 71) lembra que "um símbolo é uma lei ou regularidade do futuro indefinido". Oras, excetuando as palavras, que são símbolos, essas páginas demonstram que o Coringa é quase totalmente destituído de regularidade e objetivo. Havia uma chance em seis de ele se matar. Caso ele morresse, bem, toda a história acabava. Mas ele não morreu, e não havia qualquer razão para a roleta russa, exceto a total falta de razão. Frost observou bem que o Coringa não era muito de pensar. Pensamentos são terceiridade, a categoria fenomenológica menos presente na composição do personagem. 


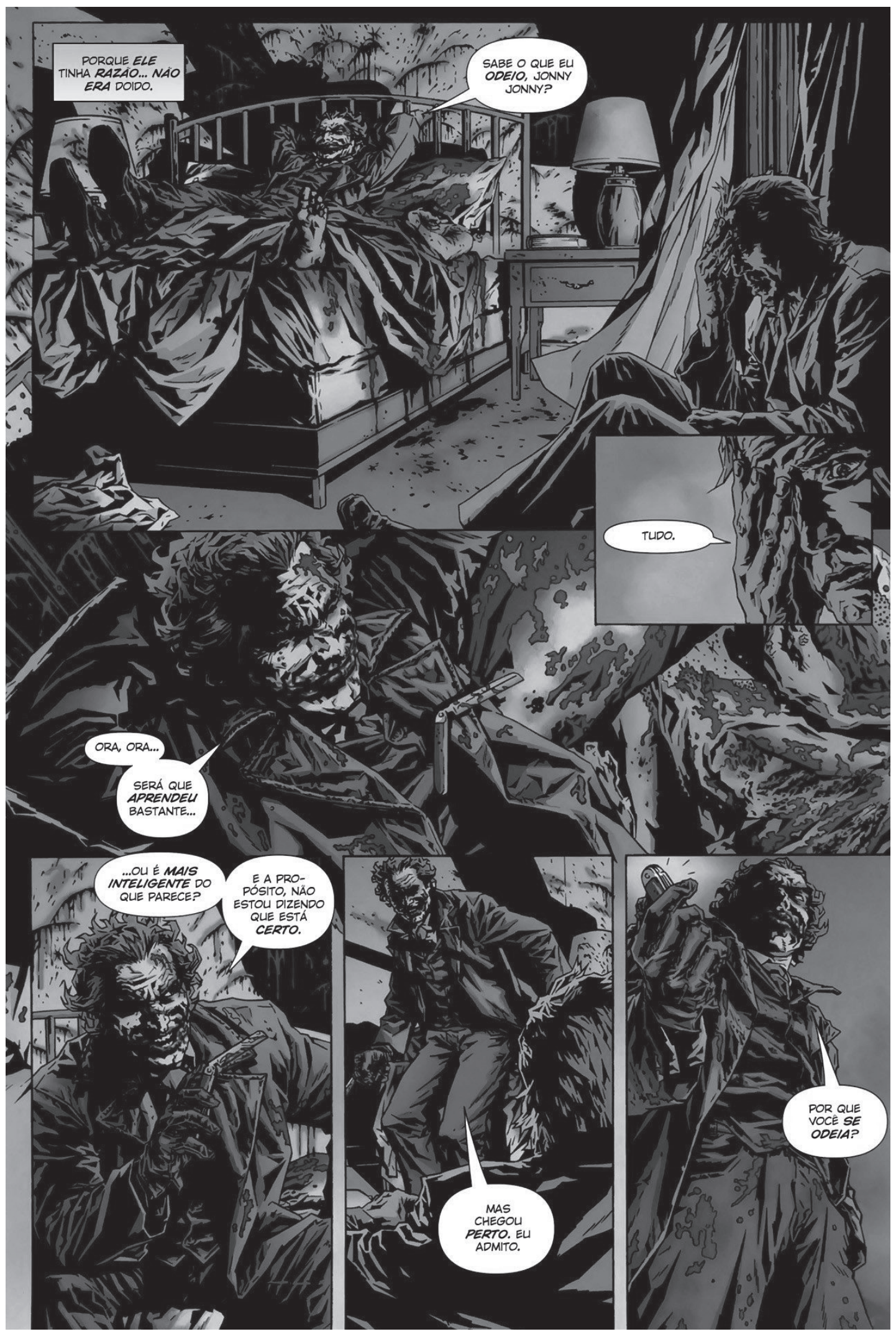

Figura 4. Terceiridade

Fonte: Azarello e Bermejo (2009, p. 108). 
Chegou-se ao ponto em que fica clara a quase ausência de terceiridade na construção do Coringa. Johnny Frost e o palhaço do crime entraram no apartamento de um casal idoso. O apartamento foi escolhido aleatoriamente, e Frost só percebeu tarde demais o porquê de estarem lá. Não havia qualquer porquê. Foi então que Johnny vislumbrou um único fragmento de terceiridade, algo que explicasse as ações até então. A resposta possível era a de que o Coringa odiava tudo. Essa seria a explicação plausível para a torrente de ações sádicas e sem sentido do personagem. E mesmo a única resposta lógica apenas "chegou perto".

O vermelho-sangue é semelhante ao vermelho na boca do Coringa. Os jorros de sangue na parede se confundem com sorrisos ao contrário, como se o próprio ato de sorrir fosse posto em questão pelo psicopata. $\mathrm{O}$ assassinato brutal e sem sentido é um ícone de sua conduta imprevisível. Não havia dinheiro, não havia drogas, não eram inimigos, não havia nada que o Coringa pudesse querer desse casal. Enfim, a cena toda é um ícone de sua conduta caótica.

Os jorros de sangue na parede são indícios dos golpes feitos com uma navalha. Centenas deles. Pode-se induzir que o pobre casal teve uma morte horrível e sofrida. A expressão e postura de Frost indicam também a perturbação de presenciar tal cena grotesca. Sua cabeça pende para frente, no primeiro quadro, e seus olhos miram o chão, em um provável gesto de desagrado.

Por fim, a quase completa ausência de terceiridade, paradoxalmente simboliza a mente distorcida e as ações cruéis do Coringa. A única regularidade do personagem é justamente a falta de regularidade. Assim, o Coringa é um símbolo do caos, encarnado na sua forma mais horripilante e sádica: a de um psicopata sem propósito.

\section{Considerações Finais}

As quatro páginas escolhidas da graphic novel não são suficientes para mostrar toda a sutileza da obra, mas são suficientes para demonstrar como o palhaço do crime se comporta. Sob a perspectiva das categorias fenomenológicas de C.S. Peirce, a primeiridade e secundidade são mais intensas na construção do personagem e no desenvolvimento de suas ações. Enquanto primeiridade, Coringa é o caos. Já na secundidade ele é uma força bruta que se coloca contra tudo, além de ser um par opositor ao seu antagonista, o Batman. Apesar do homem morcego não ter aparecido nas páginas escolhidas para esse estudo, sua presença invisível é constante. Como um código binário, Batman e Coringa são totalmente opostos.

Curiosamente a terceiridade, isto é, a generalização de algum fenômeno, é a própria inconstância do Coringa. Na sua loucura inconstante se constrói uma constância. O Coringa é um personagem difícil de ser classificado, mas o suporte da fenomenologia e da semiótica possibilitou traçar um panorama, mesmo que breve e incompleto, da sua loucura e crueldade.

\section{Referências}

AZARELlO, Brian; BERMEJO, Lee. Coringa. São Paulo: Panini Comics, 2009.

EISNER, Will. Quadrinhos e arte seqüencial. São Paulo: Martins Fontes, 1989.

MCCLOUD, Scott. Desvendando os quadrinhos. São Paulo: Makron Books, 1995.

PEIRCE, Charles Sanders. Collection paper. In: HARTSHORNE, Charles; WEISS, Paul; BURKS, Arthur (Org.). Collected papers of charles sanders Peirce. Cambridge: Harvard University Press, 1931-58. 8 v. . Semiótica. São Paulo: Perspectiva, 2003. . Semiótica e filosofia. São Paulo: Cultrix, 1975.

PIRES, J. B. Vida e obra de Charles Sanders Peirce e as bases para o estudo da linguagem fotográfica. Revista Discursos Fotográficos, Londrina, v. 4, n. 4, p. 145-160, 2008.

SANTAELLA, Lúcia. Estética: de Platão a Peirce. 2. ed. São Paulo: Experimento, 1994. 
